\title{
Alstroemeriaceae no estado do Rio de Janeiro
}

Marta Camargo de Assis ${ }^{1}$

\begin{abstract}
RESUMO
(Alstroemeriaceae no estado do Rio de Janeiro)Neste trabalho são apresentadas as espécies de Alstroemeriaceae do estado do Rio de Janeiro, Brasil. A família é representada na área pelo gênero Alstroemeria, incluindo cinco espécies: $A$. caryophyllaea Jacq., A. cunha Vell., A. foliosa Mart. ex Schult. \& Schult. f., A. isabelleana Herb., A. radula Dusén e pelo gênero Bomarea incluindo apenas a espécie B. edulis (Tussac) Herb. Novas sinonimizações, chaves de identificação, descrição das espécies, ilustrações e comentários são aqui apresentados.
\end{abstract}

Palavras-chave: Alstroemeriaceae, florística, Rio de Janeiro, Brasil.

\begin{abstract}
(Alstroemeriaceae in the Rio de Janeiro state) This paper presents the species of Alstroemeriaceae of Rio de Janeiro State, Brazil. The family is represented in the area by two genera: Alstroemeria and Bomarea. Alstroemeria includes five species: A. caryophyllaea Jacq., A. cunha Vell., A. foliosa Mart. ex Schult. \& Schult. f., A. isabelleana Herb. and A. radula Dusén. Bomarea includes just one species, B. edulis (Tussac) Herb. New synonyms, key to genera and species, descriptions, illustrations and comments are presented.
\end{abstract}

Key-words: Alstroemeriaceae, floristic, Rio de Janeiro, Brazil.

\section{INTRODUÇÃO}

Alstroemeriaceae é uma família neotropical distribuída desde a região central do México até o sul da América do Sul, com cerca de 190 espécies (Assis 2001). A família é dividida em três gêneros: Alstroemeria L. (incluindo Schickedantzia Pax e Taltalia E. Bayer), Bomarea Mirb. e Leontochir Phil. (Sanso \& Xifreda 1999; 2001), sendo que no Brasil estão representados os gêneros Alstroemeria e Bomarea. No Rio de Janeiro, foram encontradas seis espécies, distribuídas nos dois gêneros.

Em função de sua beleza e durabilidade, essas plantas foram introduzidas como ornamentais na Europa no século XV e desde então vários trabalhos de melhoramento tem sido realizado, primeiramente à partir do grupo de espécies chilenas, tornando o lírio inca ou madressilva uma flor de corte muito popular tanto nos países europeus quanto nos Estados Unidos e Japão (Sanso et al. no prelo).

Este trabalho tem como objetivo contribuir para a flora do estado do Rio de
Janeiro e foi baseado em observações de campo e na análise de materiais botânicos depositados em herbários nacionais e estrangeiros. Apenas as novas sinonímias são aqui apresentadas.

\section{Tratamento taXonôMico}

\begin{abstract}
Alstroemeriaceae
Ervas eretas ou volúveis, 0,3-4 m alt.; rizoma simpodial, raízes delgadas ou espessadas. Folhas geralmente ressupinadas, alternas, membranáceas, cartáceas ou coriáceas, ambas as faces glabras ou face adaxial papilosa, lineares, lanceoladas, elípticas, obovais, oblongas a espatuladas. Inflorescências terminais em cimeiras umbeliformes simples ou compostas, raro flores solitárias. Brácteas foliosas, reduzidas ou ausentes. Flores epíginas, bissexuais, actinomorfas ou zigomorfas, creme, esverdeadas, amareladas, alaranjadas, avermelhadas ou lilases. Tépalas petalóides, livres, as externas geralmente sem padrão de
\end{abstract}

Artigo recebido em 12/2003. Aceito para publicação em 04/2004.

${ }^{1}$ Centro Nacional de Pesquisa de Monitoramento por Satélite (CNPM/EMBRAPA), Av. Dr. Júlio Soares de Arruda, 803, 13088-300 Campinas, SP, Brasil. marta@cnpm.embrapa.br 
manchas ou menos manchadas que as internas. Tépalas internas punctadas, maculadas, listradas ou variegadas, a inferior geralmente mais estreita; margem proximal fortemente involuta formando um tubo revestido por tricomas glandulares secretores de néctar. Estames 6, exclusos ou inclusos; filetes livres, cilíndricos, complanados na base e subulados no ápice; anteras pseudobasifixas, deiscência introrsa e longitudinal. Estilete excluso ou incluso, trígono; estigma trífido, ramos papilosos. Ovário trilocular ou raramente unilocular; óvulos anátropos de placentação axilar ou parietal. Fruto cápsula loculicida, raro indeiscente. Sementes globosas com ou sem sarcotesta.

\section{Chave para identificação dos gêneros}

1. Ervas volúveis, flores actinomorfas, semente com sarcotesta Bomarea edulis $1 '$. Ervas eretas, flores zigomorfas, raro actinomorfas, semente sem sarcotesta Alstroemeria

\section{Alstroemeria L.}

Ervas eretas; ramos vegetativos e reprodutivos diferentes entre si. Folhas geralmente resupinadas, glabras ou papilosas na face adaxial, lâminas linear-lanceoladas, oblongas, elípticas ou espatuladas. Inflorescência em cimeira umbeliforme simples ou composta. Flores zigomorfas, pendentes ou patentes, campanuladas ou tubulosas, protrândricas; tépalas livres, eretas ou reflexas; as externas e internas com padrões de manchas rubro-maculadas, rubropunctadas, rubro-listadas ou rubro-variegadas; nectários perigonais na base de 2-3 tépalas internas. Estames 6, filetes cilíndricos, glabros ou papilosos na base, anteras alongadas; ovário trilocular, numerosos óvulos anátropos de placentação axilar ou parietal; estilete simples, estigma trífido. Cápsula loculicida. Sementes sem sarcotesta, globosas, cinéreoacastanhadas.

O gênero compreende cerca de 90 espécies restritas à América do Sul, ocorrendo desde a Venezuela ( $3^{\circ}$ Norte) até a Terra do Fogo, Argentina $\left(53^{\circ} \mathrm{Sul}\right)$, com dois principais centros de distribuição, um no Chile (se extendendo para o Peru, Bolívia e Argentina) e o segundo através do Brasil, Paraguai e Argentina (Bayer 1987; Aker \& Healy 1990).

No Brasil, ocorrem cerca de 38 espécies de distribuição peri-amazônica concentrada basicamente na porção leste do país, ocorrendo em quase todos os tipos de hábitats: florestas, cerrados, campos de altitude, brejos, afloramentos rochosos e caatingas, em altitudes que variam de $300 \mathrm{~m}$, na Amazônia, a $2.300 \mathrm{~m}$, na Serra do Itatiaia (Assis 2001; 2002; 2003; Assis \& Mello-Siva 2002).

\section{Chave para identificação das espécies de Alstroemeria}

1. Folhas cartáceas ou coriáceas.

2. Folhas papilosas na face adaxial, pedicelo papiloso; flores patentes, campanuladas, amarelas, alaranjadas ou avermelhadas; tépalas internas rubro-listradas (afloramentos rochosos) 3. A. foliosa

2'. Folhas geralmente glabras, pedicelo glabro; flores pêndulas, tubulosas, rosadas, alaranjadas, avermelhadas ou esverdeadas; tépalas internas rubro-listadas e maculadas (locais úmidos)

4. A. isabelleana

1'. Folhas membranáceas.

3. Folhas papilosas na face adaxial; ramos e pedicelos papilosos; flores vermelhas a amareladas ou creme-esverdeadas; tépalas lanceoladas, ápice caudado, sem manchas ou internas rubro-punctadas; filetes 3-8 cm compr.; estilete 3,2-5 cm compr. (matas de altitude) 
3'. Folhas geralmente glabras; ramos e pedicelos glabros; flores avermelhadas, carmim ou rosadas; tépalas espatuladas, obovadas ou lanceolado-espatuladas, ápice não caudado, internas rubro-maculadas e/ou listradas; filetes até 3,5 cm compr.; estilete até $3,2 \mathrm{~cm}$ compr.

4. Flores odoríferas, avermelhadas, carmim ou rosadas; tépalas externas espatuladas, ápice mucronado; tépalas internas rubro-maculadas, espatuladas, ápice cuspidado, agudo ou acuminado; filetes glabros (matas) .... 1. A. caryophyllaea 4'. Flores inodoras, vermelho-alaranjadas; tépalas externas obovadas, ápice retuso ou rotundo; tépalas internas rubro-listradas e maculadas, lanceolado-espatuladas, ápice agudo ou acuminado; filetes papilosos na base (matas) 2. A. cunha

1. Alstroemeria caryophyllaea Jacq., Pl. Hort. Schoenbr.6: 33 t. 465. 1804.

Tipo: Tab. 465 de Jacq., Pl. Hort. Schornbr. 6: 33. 1804.

Alstroemeria pelegrina Vell., Fl. flumin. 3(1): 131 tab. 119. 1829. Nom. illeg. non A. pelegrina L., Planta Alstroemeria Amoen. acad. 6: 254. 1762.

Alastroemeria fluminensis M.Roem., Fam. Nat. Syn. Monogr. 4: 260. 1847. Tipo: Fig. 119 de Vellozo, Fl. flumin. 3(1). 1831. Syn. nov. Alstroemeria rubra Morel, Rev. Hort. serie 4(2): 81. Fig. 5. 1853. Tipo: Fig. 5 de Morel, Rev. Hort. Serie 4(2): 81. 1853.Syn. nov.

Figura 1: a-c

Erva ereta, 0,4-0,7 m alt.; ramos cilíndricos, glabros. Folhas do ramo vegetativo resupinadas, membranáceas, concentradas na porção distal do ramo; $2,5-8 \times 0,3-1,5 \mathrm{~cm}$, elípticas a elíptico-espatuladas, ápice agudo, base longa e estreitamente atenuada, ambas as faces glabras, nervuras não proeminentes. Folhas do ramo reprodutivo resupinadas ou não, não amplexicaules, membranáceas, distribuídas por todo ramo, $0,8-2,2 \times 0,1-0,3 \mathrm{~cm}$, lineares a linear-lanceoladas, ápice agudo a acuminado, base cuneada, ambas as faces glabras, nervuras não proeminentes. Cimeira umbeliforme simples, pedicelo glabro, $2-3 \mathrm{~cm}$ compr. Brácteas foliosas membranáceas, 2,5$3,5 \times 0,1-0,2 \mathrm{~cm}$; bractéolas, $0,7 \times 0,4 \mathrm{~cm}$, linearlanceoladas. Flores ereto-patentes, odoríferas, campanuladas, avermelhadas, carmim ou rosadas, 5-6 cm compr. Tépalas externas sem manchas, semelhantes entre si, espatuladas, ápice mucronado, base fortemente atenuada; a superior 4,5-5,5 x 1,2 cm; as inferiores 3,5 x $0,7-1 \mathrm{~cm}$. Tépalas internas rubro-maculadas, as superiores iguais entre si, 4,4-5 x 0,8 cm, espatuladas, ápice cuspidado; a inferior 2,3 $\mathrm{x}$ 0,2-0,5 cm, lanceolada, ápice cuspidado, base atenuada, margem distal inteira ou ligeiramente crenulada. Estames exclusos, filetes glabros, ca. $3 \mathrm{~cm}$ compr. Estigma excluso, estilete glabro, ca. 3,2 cm compr. Cápsula elipsóide, ca. $1,4 \times 1,3 \mathrm{~cm}$.

Nome popular: Madressilva, lírio inca.

Material examinado: Cabo Frio: Fazenda Tiririca, s.d. (fl), F. Sellow 184 (B); Itaipuaçu: Estrada do Rio Itaipuaçu, 27/IV/1936 (fl), $A$. C. Brade 15298 (RB); Pico Alto Moirão, 26/ VIII/1981 (fl), R. H. P. Andreata et al. 102 (RUSU); 10/VII/1982 (fl), F. E. Miranda \& M. C. Carvalho 13 (GUA); Rio de Janeiro: Silvestre, VII/1913 (fl), F. C. Hoehne 148 (R).

Raramente encontrada em estado nativo em locais úmidos e sombreados de Minas Gerais e Rio de Janeiro, é cultivada em toda a Região sul e sudeste do Brasil. Esta espécie é de fácil identificação através de suas flores perfumadas e tépalas internas que apresentam faixa transversal esbranquiçada ou amarelada. Floresce principalmente em junho e julho e frutifica em setembro e outubro.

Alstroemeria caryophyllaea está relacionada a A. capixaba M. C. Assis pelos ramos vegetativos que são muito semelhantes, mas diferenciam-se pelas flores. Em $A$. caryophyllaea, elas são odoríferas e com tépalas externas sem manchas, enquanto que em $A$. capixaba elas não possuem odor e todas as tépalas são maculadas. 

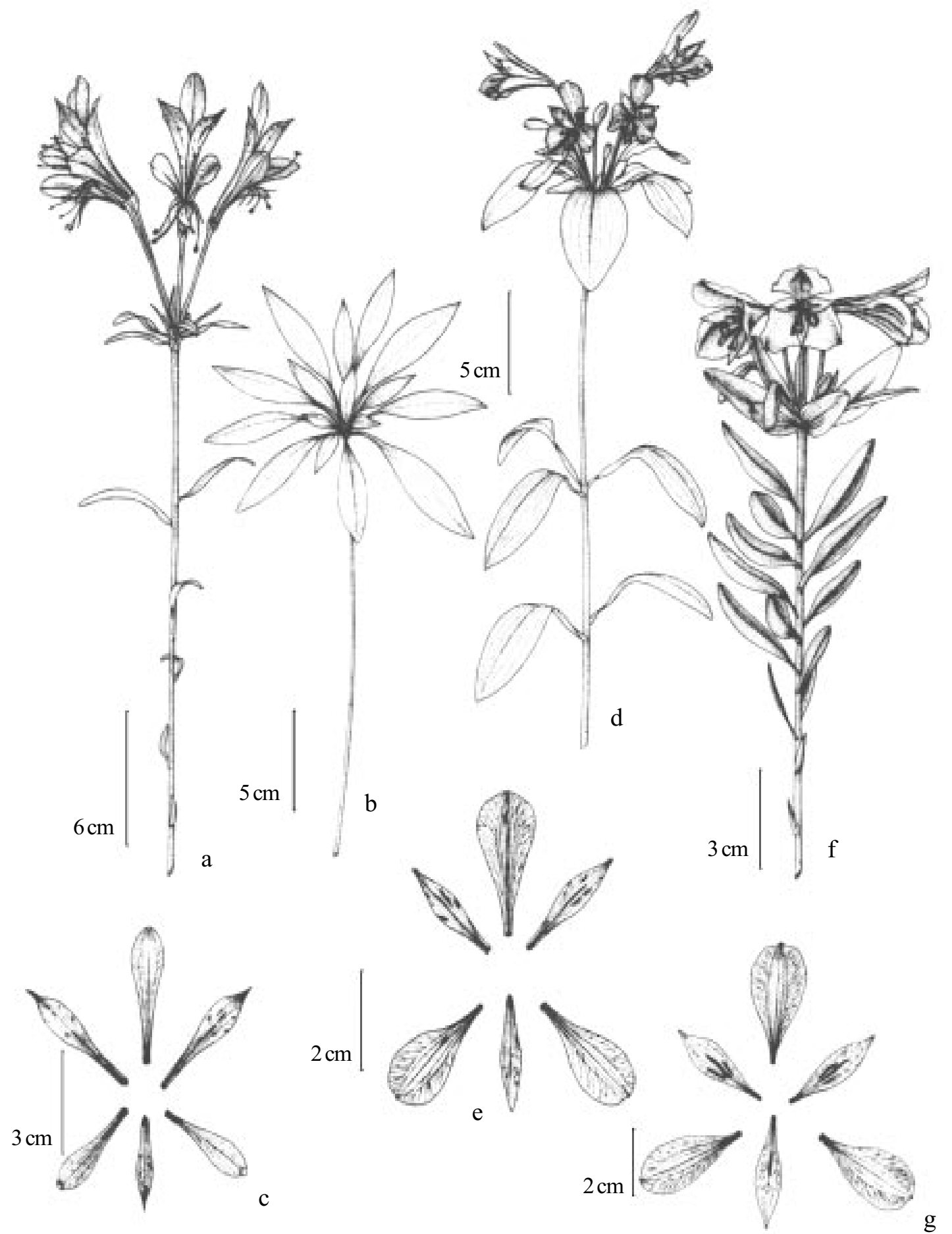

Figura 1 - a-c Alstroemeria caryophyllaea: a - Ramo reprodutivo; b - Ramo vegetativo; c - Tépalas externas sem manchas e internas maculadas (Assis 324). d-e A. cunha: d - Ramo reprodutivo; e - Tépalas externas sem manchas e internas maculadas (Hunt 6489). f-g A. foliosa: f - Ramo reprodutivo; g - Tépalas externas sem manchas e internas lineadas (Shepherd s.n., UEC 87719). 
Na descrição de A. rubra, o autor salienta apenas sua beleza e características agronômicas, não dando detalhes botânicos sobre a espécie. Observando-se a ilustração nota-se claramente que trata-se de um sinônimo de A. caryophyllaea.

A descrição de A. pelegrina, Vellozo conta apenas com caracteres genéricos. A observação do material tipo desta espécie juntamente com o local de coleta me permitiram concluir que esse nome representa a mesma espécie: A. caryophyllaea.

No protólogo de $A$. fluminensis, a prancha de $A$. pelegrina é citada. Roemer atribuiu um outro epíteto à espécie, já que o anteriormente dado por Vellozo é um homônimo posterior ao de Linnaeus. Sendo assim, $A$. fluminensis é sinônimo de A. caryophyllaea.

2. Alstroemeria cunha Vell., Fl. flumin. 3(1): 131. 1829 (1825); Icon. 3: 121. 1831 (1827). Tipo: Fl. flumin. Icon. 3: 121. 1831 (1827).

Alstroemeria nemorosa Gardner, Bot. Mag. 68(15): 3958. 1842. Tipo: Brasil. Rio de Janeiro. Serra dos Órgãos, 3/IV/1837 (fl), $G$. Gardner 698 (lectótipo, BM !; isolectótipos, K !). Syn. nov.

Alstroemeria argentovittata Lem. Ill. Hort. 4: Misc. 88. 1857; 6: 1 P. 192. 1859. ("argento-vittata"). Tipo: P1. 192 de Lemaire, Ill. Hort. 6: 1859 !. Syn. nov.

Figura 1: d-e

Erva ereta 0,2-1,5 m alt.; ramos cilíndricos, glabros. Folhas do ramo vegetativo resupinadas, membranáceas, concentradas no terço distal do ramo, 2,5-10(-13) x 1-3(-4,8) $\mathrm{cm}$, elípticas ou obovadas, ápice agudo, base atenuada, glabras ou papilosas na face adaxial, face abaxial glabra, nervuras não proeminentes. Folhas do ramo reprodutivo resupinadas, não amplexicaules, membranáceas, distribuídas por todo o ramo, (1,7-)2,5-10,5(-14) x (0,3-)0,5$2,2(-4) \mathrm{cm}$, elípticas ou oblongas, ápice agudo ou acuminado, base atenuada, glabras ou papilosas na face adaxial, face abaxial glabra, nervuras não proeminentes. Cimeira umbeliforme simples, pedicelo glabro, $2-5(10,5) \mathrm{cm}$ compr. Brácteas foliosas, membranáceas, 2,5$5,7(-8)$ x 1-2,5 cm; bractéolas não vistas. Flores patentes, inodoras, campanuladas, vermelhoalaranjadas, (2,5-)3-4,5 cm compr. Tépalas externas sem manchas, semelhantes entre si, obovadas, ápice retuso a rotundo, base atenuada; a superior 2,4-3 x 1-1,3 cm; as inferiores 2,6-2,8 x 1-1,2 cm. Tépalas internas rubro-listadas e maculadas, semelhantes entre si, lanceolado-espatuladas, ápice agudo ou acuminado, margem distal inteira ou ligeiramente crenulada; as superiores $2,4-2,8$ x 0,3-0,7 cm; a inferior 2,2-2,4 x 0,4 cm. Estames exclusos ou inclusos, filetes papilosos no terço proximal, 2,2-3,5 cm compr. Estigma incluso, estilete glabro, 2,2-3 cm compr. Cápsula não vista.

Material examinado: Serra dos Órgãos, 9/ VII/1940 (fl), A. C. Brade 16326 (RB); Córrego Roncador, elev. 1700 m, 15/VII/1940 (fl), A. C. Brade 16375 (F); 3/VIII/1966 (fl), D. R. Hunt 6489 (UB); Nova Friburgo: Estrada para o pico Nova Caledônia, 14/I/1985 (fl), J. F. A. Baumgratz et al. 306 (RB); Petrópolis: Serra dos Órgãos, XII/1943 (fl), $O$. C. Góes \& D. Constantino 49386 (RB); Teresópolis: Serra dos Órgãos, elev. 1600 m, 19/IX/1929 (fl), A. C. Brade 9262 (R); 26/ VI/1942 (fl), Dionísio \& Otavio 269 (RB); 15/X/1970 (fl), J. Garcia 104 (R); 1970 (fl), J. Garcia 375 (R); Campo das Antas, III/1942 (fl), J. L. Pessoa \& A. L. Gomes s.n. (R 37272); 22/V/1948 (fl), B. Carris s.n. (RB 62501); 9/XII/1960 (fl), A. Castellanos 23148 (GUA); 21/XII/1975 (fl), T. C. Pires 11 (RB); XII/1975 (fl), G. Lott 13 (RB); 21/XII/1975 (fl), J. P. P. Carauta 1844 (GUA, SPF); $7 /$ IX/1981 (fl), D. S. Souza et al. 506 (GUA).

É freqüentemente encontrada no Espírito Santo, Minas Gerais, Rio de Janeiro, São Paulo e Paraná, ocorrendo no interior de florestas estacionais semidecíduas. No Rio de Janeiro, é abundante na Serra dos Órgãos. Floresce esporadicamente o ano inteiro, mais intensamente de novembro a março.

Alstroemeria cunha possui grande variação na dimensão dos ramos e na 
dimensão, disposição e no indumento das folhas. As flores podem apresentar estames exclusos ou inclusos e também variam bastante nas dimensões. Assim, o que caracteriza a espécie é o ramo reprodutivo com folhas membranáceas distribuídas por todo o ramo, juntamente com as flores de tépalas externas sem máculas e tépalas internas rubro-listradas e maculadas.

Alstroemeria cunha se assemelha a $A$. inodora Herb. que ocorre no mesmo tipo de habitat. No entanto, diferenciam-se pelas flores de tépalas externas rubro-variegadas em $A$. inodora e tépalas externas sem manchas em A. cunha.

Os caracteres diagnósticos de $A$. nemorosa, abrangem a variação fenotípica de A. cunha. Comparando-se os tipos e locais de ocorrência de $A$. cunha e $A$. nemorosa, fica claro que tratam-se da mesma espécie.

Alstroemeria argentovittata recebeu este nome por possuir as folhas do ramo vegetativo esbranquiçadas a prateadas na região da nervura central da face abaxial. Este fato é comum a muitas espécies de Alstroemeria, principalmente em folhas mais jovens. A descrição da flores vermelhoalaranjadas de tépalas internas rubromaculadas, juntamente com o comentário de que esta espécie é affinis de A. nemorosa e da observação da ilustração, me levaram a concluir que esta espécie é sinônimo de $A$. cunha.

3. Alstroemeria foliosa Mart. ex Schult. \& Schult.f. in Roem. \& Schult., Syst. veg. 7(1): 740. 1829. Tipo: Brasil. São Paulo. Itu: XII (fl), C. P. F. Martius s.n. (holótipo, M 293!).

Alstroemeria foliosa var. floribunda Beauverd, Bull. Herb. Boissier 2(6): 587, fig. 3-4. 1906. Tipo: Brasil. Minas Gerais. Ouro Preto: Pico do Itacolomi, 31/VIII/1904 (fl), $L$. Damazio 1553 (holótipo, G !). Syn. nov.

Figura 1: f-g

Erva ereta 0,4-0,6 m alt.; ramos cilíndricos, pubérulos. Folhas do ramo vegetativo resupinadas, cartáceas, congestamente distribuídas por todo o ramo, 2-5 x 0,2-1 cm, elípticas a oblongas, ápice agudo a acuminado, base atenuada, face adaxial papilosa, abaxial glabra, nervuras proeminentes em ambas as faces. Folhas do ramo reprodutivo resupinadas, não amplexicaules, cartáceas, distribuídas na metade distal do ramo, 2-5 x 0,2-1 cm, elípticas a oblongas, face adaxial papilosa, abaxial glabra, nervuras proeminentes em ambas as faces. Cimeira umbeliforme simples, pedicelo papiloso, 2-3,5 cm compr. Brácteas foliosas, cartáceas, 2,2-3,5 x 0,5-0,8 cm, elípticas a oblongas, ápice agudo a acuminado, base atenuada; bractéolas ausentes. Flores patentes, inodoras, campanuladas, amarelas ou vermelhas, 4-5,5 cm compr. Tépalas externas sem manchas, semelhantes entre si, obovadas, ápice mucronado, base atenuada; a superior 3-4, x 1,3-2 cm; as inferiores, $3-4,5$ x 1,1-1,8 cm. Tépalas internas rubrolineadas, semelhantes entre si, elípticas, ápice acuminado, base atenuada, margem distal ligeiramente crenulada; as superiores 2,8-4,5 x 0,6-1,2 cm; a inferior 3-4 x 0,4-0,9 cm. Estames inclusos, filetes glabros, 2,3-2,6 cm compr. Estigma incluso, estilete glabro ca. $2,3 \mathrm{~cm}$ compr. Cápsula não vista.

Material examinado: Itatiaia: Sítio de Ramos, elev. 2300 m, I/1899 (fl), E. Gounelle s.n. (G); Parque Nacional de Itatiaia, 24/II/1948 (fl), M. G. Ferri s.n. (SPF 85373); 24/I/1987 (fl), T. B. Cavalcanti et al. 11 (SPF); 22/XII/ 1989 (fl), R. B. Torres et al. s.n. (UEC).

Alstroemeria foliosa é encontrada em afloramentos rochosos nas serras de Minas Gerais, Rio de Janeiro e São Paulo, florescendo de novembro a abril.

É facilmente caracterizada pelas tépalas externas largamente obovadas e internas elípticas, rubro-listadas. Além disso, a face adaxial da folhas e os pedicelos são papilosos.

Juntamente com a descrição de $A$. foliosa, Martius descreveu duas variedades: A. foliosa var. angustifolia, caracterizada pelas folhas do ramo reprodutivo lineares, esparsamente distribuídas, e pela umbela com 1-6 flores, e A. foliosa var. humilior, caracterizada pelas folhas do ramo reprodutivo linear-lanceoladas, concentradas na região 
mediana do ramo, e umbela com 2-4 flores. Estas duas variedades foram descritas a partir de material coletado na Serra da Piedade, Minas Gerais. Examinando-se o holótipos das variedades, espécimens herborizados e observando-se as populações em campo, notou-se que o que Martius classificou como variedades de $A$. foliosa, são na realidade, pertencentes a outra espécie, A. plantaginea Mart. ex Shult. \& Schult. f. Esta espécie diferencia-se de $A$. foliosa por apresentar flores de tépalas externas obovado-espatuladas, internas oblongo-espatuladas, rubro-maculadas e pelas folhas e pedicelos glabros.

Beauverd (1906) descreveu A. foliosa var. floribunda distinguindo-a das outras duas precedentes pelas "foliis lineari-obtusiusculis mucronulatis, in medio caule confertis; umbella ramosa 7-34 flora". Analisando-se o material em campo e herborizado, nota-se que estas características estão dentro da variação da espécie.

4 Alstroemeria isabelleana Herb., Amaryllidaceae 88, tab. 6, figs. 4-6. 1837.("isabellana")

Tipo: Brasil. Rio Grande do Sul: 1835 (fl), $A$. Isabelle s.n. (holótipo, $\mathrm{K}$ !; foto holótipo, $\mathrm{F}$ )

Alstroemeria isabelleana Herb. var. longifolia Seub. ex Schenk. in Martius \& Eichler, Fl. bras. 3: 171. 1855. Tipo: Brasil. Rio Grande do Sul: s.d., F. Sellow 134, 135, 136, 137 (sintipo, B!, BR!). Syn. nov.

Alstroemeria campaniflora Hand.Mazzt., Denkschr. Kaiserl. Akad. Wiss., Wien. Math.-Naturwiss. K1. 79: 213; tab. 19, figs. 26. 1908. Tipo: Brasil. São Paulo: São Bernardo do Campo, 1902 (fl), A. Wachsmund s.n. (holótipo, WU 1225 !; isótipo, B !). Syn. nov. Alstroemeria regnelliana Kraenzl., Bot. Jahrb. Syst. 50 Beibl. 112: 3. 1913. Tipo: Brasil. Minas Gerais: Caldas, 21/XI/1874 (fl), A. F. Regnell III 1796 (holótipo, B !). Syn. nov.

Alstroemeria butantanensis Hoehne, Revista Mus. Paul. Univ. São Paulo 11: 485. Tab. Única. 1919. Tipo: Brasil. São Paulo: São Paulo, 14/XII/1917 (fl), F. C. Hoehne 1075 (lectótipo, F !, isolectótipo, SPF !). Syn. nov.
Alstroemeria viridiflora Ravenna, Onira 4(10): 34. 2000. Tipo: Brasil. Minas Gerais. Carangola: Serra da Araponga, Fazenda Neblina, alt. 1.400 m, XII/1994 (fl), L. S. Leoni 2736 (holótipo, GFJP !; isótipo, SPF !). Nom. illeg., non Alstroemeria viridiflora Warm., Symbolae 13: 118. 1872. Tipo: Brasil. Minas Gerais. Lagoa Santa, s.d. (fl), J. E. B. Warming 1094 (holótipo, C !). Syn. nov.

Figura 2: a-c

Erva ereta, 0,42-1,5 m alt.; ramos angulosos, papilosos a glabrescentes no terço proximal. Folhas do ramo vegetativo resupinadas ou não, coriáceas, sésseis, distribuídas por todo o ramo, $3-16$ x 0,5-1 cm, elíptico-lanceoladas, ápice acuminado ou arredondado, base atenuada, ambas as faces glabras com nervuras proeminentes, raro papilosa na face adaxial. Folhas do ramo reprodutivo resupinadas ou não, semiamplexicaules ou não, coriáceas, distribuídas no terço proximal do ramo, $3-16 \times 0,5-1 \mathrm{~cm}$; elíptico-lanceoladas, ápice acuminado ou arredondado, base atenuada, ambas as faces glabras com nervuras proeminentes, raro papilosa na face adaxial. Cimeira umbeliforme simples, pedicelo glabrescente, $1,5-4 \mathrm{~cm}$ compr. Brácteas foliosas ausentes ou membranáceas, 0,6-2 x 0,2-0,3 cm; bractéolas membranáceas, $0,6-3 \times 0,2-0,3 \mathrm{~cm}$. Flores pêndulas, inodoras, tubulosas, rosadas, alaranjadas, vermelhas, ou raro cremeesverdeadas, ápice esverdeado, $3-4,5 \mathrm{~cm}$ compr. Tépalas externas listadas ou sem manchas, semelhantes entre si, oblongas a espatuladas, ápice acuminado a mucronado, base atenuada; a superior ca. $3,4 \times 0,4 \mathrm{~cm}$; as inferiores ca. $3,4 \times 0,5 \mathrm{~cm}$. Tépalas internas rubro-listadas, iguais entre si, ca. $3,3 \times 0,5 \mathrm{~cm}$, espatuladas, ápice acuminado a cuspidado, base fortemente atenuada, margem distal inteira. Estames inclusos, filetes glabros, ca. $2,3 \mathrm{~cm}$ compr. Estigma incluso, estilete glabro, ca. 2,8 cm compr. Cápsula esferoidal, 1,5-2 x $1,5-2 \mathrm{~cm}$.

Material examinado: XI/1833 (fl), G. $H$. Langsdorff s.n. (K); Itatiaia: Parque Nacional 

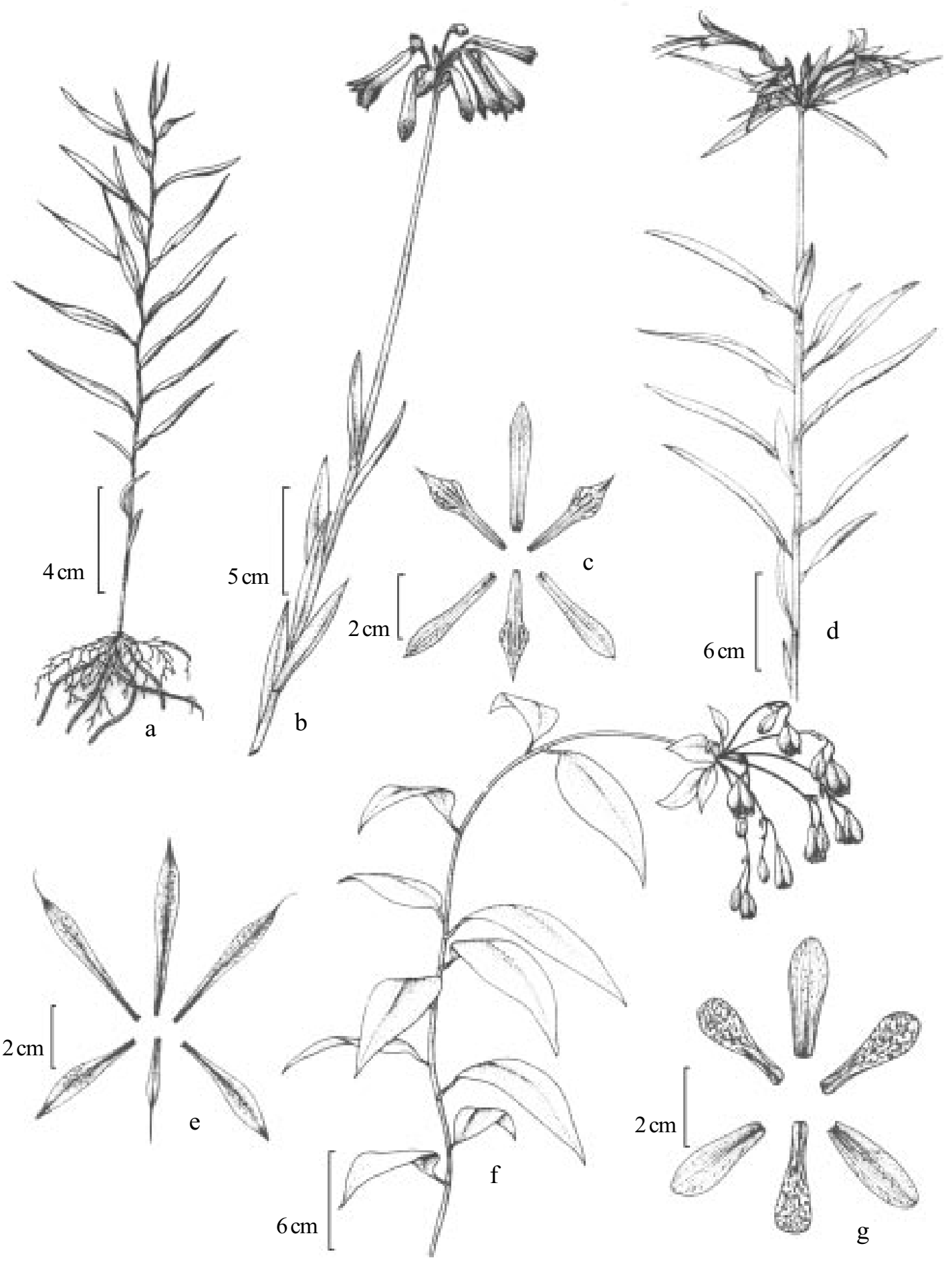

Figura 2 - a-c Alstroemeria. isabelleana: a - Ramo vegetativo; b - Ramo reprodutivo mostrando flores tubulosas e pêndulas; c - Tépalas externas sem manchas e internas listadas e maculadas (Buzato s.n., UEC 28014). d-e A. radula: DRamo reprodutivo; e - Tépalas externas e internas sem manchas e tépalas internas com ápice caudado (Hatschbach 61440). f-g Bomarea edulis: f - Hábito; g - Tépalas externas sem manchas e internas maculadas e variegadas (Assis 333). 
do Itatiaia, IV/1921 (fl), P. Occhioni s.n. (RB 16476); Retiro da Cabeça de Negro, XI/1903 (fl), C. Moreira 28 (R); 1907 (fl), A. F. M. Glaziou 6734 (F, K); Planalto, elev. 2.100 m, I/1938 (fl), A. C. Brade 16015 (B); elev. 2.300 m, 28/XII/1934 (fl), R. K. F. Pilger \& A. C. Brade 41 (RB); Prateleira, elev. $2.200 \mathrm{~m}, 8 /$ II/1945 (fl), A. C. Brade 17425 (RB); Abrigo das Acácias, 14/I/1961 (fl), B. Flaster 106 (GUA); Abrigo Rebouças, 3/XII/1964 (fl), $H$. E. Strang 646 (GUA); elev. 2650m, 24/I/1987 (fl), T. B. Cavalcanti et al. 10 (SPF); Teresópolis: Serra dos Órgãos, s.d. (fl, fr), s.c., s.n. (R 188697).

Alstroemeria isabelleana é encontrada na Argentina, Uruguai, Paraguai e Brasil, onde é freqüente em locais úmidos. No Brasil, ocorre do Rio Grande do Sul a Minas Gerais. Floresce de outubro a fevereiro, às vezes até junho. Frutifica em janeiro, fevereiro, maio e setembro.

A espécie caracteriza-se principalmente pelas flores tubulosas e pêndulas, variam de rosadas a creme-esverdeadas, sempre com ápice verde. $\mathrm{O}$ ramo vegetativo é muito semelhante aos ramos vegetativos de $A$. apertiflora Baker, A. longistyla Schenk, A. malmeana Kraenzl. e A. sellowiana Seub. ex Schenk. Todas ocorrem em brejo e apresentam o ramo vegetativo coberto por folhas linearlanceoladas, cartáceas ou coriáceas, freqüentemente adpressas ao ramo, sendo muito difícil diferenciá-las neste estágio.

Nas descrições de A. campaniflora, A. regnelliana, $A$. butantanensis e $A$. viridiflora, os autores mencionam os caracteres da folhas linear-lanceoladas, flores de ápice verde e tépalas internas rubrolistradas. Analisando essas características juntamente com os holótipos dessas espécies, observa-se que não diferem em nenhum caracter diagnóstico de A. isabelleana.

5. Alstroemeria radula Dusén, Arch. Jar. Bot. Rio de Janeiro 13: 103. 1905.

Tipo: Brasil. Rio de Janeiro: Serra do Itatiaia, elev. 1.300 m, I/1903 (fl), E. Ule s.n. (R); elev.1.850 m, V/1903 (fl), E. Ule s.n. (R!).
Alstroemeria caudiculata Ravenna, Onira 4(10): 36. 2000. Tipo: Brasil. Espírito Santo. Domingos Martins. Parque Estadual de Pedra Azul, 11/II/1998 (fl), M. F. Vasconcelos s.n. (holótipo, BHCB !). Syn. nov.

Figura 2: d-e

Erva ereta 0,3-0,8 m alt.; ramos cilíndricos, papilosos a glabrescente. Folhas do ramo vegetativo resupinadas, não amplexicaules, membranáceas, concentradas no terço distal do ramo, 3-8,5 x 0,5-2,2 cm, elípticas, ápice acuminado, base atenuada, face adaxial papilosa a glabrescente, abaxial glabra, nervuras não proeminentes. Folhas do ramo reprodutivo resupinadas, não amplexicaules, membranáceas, esparsamente distribuídas por todo o ramo, 6,5-14 x 1-2,5 cm, espatuladas a lanceoladas, ápice agudo a acuminado, base atenuada, face adaxial papilosa a glabrescente, abaxial glabra, nervuras não proeminentes. Cimeira umbeliforme simples, pedicelo papiloso a glabrescente no terço proximal, 1,5-3,5 cm compr. Brácteas foliosas membranáceas, 1,2$8,5 \times 0,4-1,5 \mathrm{~cm}$; bractéolas membranáceas, $2,5-3,5 \times 0,1-0,2 \mathrm{~cm}$. Flores patentes, inodoras, campanuladas, vermelho-amareladas ou creme-esverdeadas, 4-7 cm compr. Tépalas externas sem manchas, semelhantes entre si, lanceoladas, ápice caudado, base atenuada; a superior reflexa, 4-5,5 x 0,5-0,7 cm; as inferiores 3,5-3,7 x 0,5-0,7 cm. Tépalas internas rubro-punctadas, semelhantes entre si, linearlanceoladas, ápice caudado, base atenuada, margem distal inteira; as superiores 3-6 x 0,3$0,5 \mathrm{~cm}$; a inferior ligeiramente revoluta, 3-3,3 $x$ 0,2-0,3 cm. Estames exclusos, filetes glabros, ca. 3-8 cm compr. Estigma excluso, estilete glabro, 3,2-5 cm compr. Cápsula elipsóide, ca. $2,4 \times 1,5 \mathrm{~cm}$.

Material examinado: Itatiaia: Itatiaia, s.d. (fl), E. Ule 29 (R); s.d., s.c. s.n. (R 193309); Fazenda Henrique, II/1899 (fl), E. Gounelle s.n. (G); 26/XII/1915 (fl), P. Campos Porto 169, (RB); II/1947 (fl), B. Lutz s.n. (R); VI/ 1952 (fl), B. Lutz s.n. (R 188699); Campo Itatiaia, V/1906 (fl), H. Lüderwaldt 6287 (SP); Trilha entre Ponte Maromba e Macieiras, 
$22^{\circ} 27^{\prime} \mathrm{S} 44^{\circ} 39^{\prime} \mathrm{W}$, elev. $1.200-1.900 \mathrm{~m}, 10 / \mathrm{I} /$ 1929 (fl), L. B. Smith 1792 (F); Serra da Mantiqueira, Mauá, acima do Rio Preto, elev. 1.500 m, 4/III/1931 (fl), R. W. Kaempfe 442 (B); Macieiras, 6/III/1951 (fl), $\quad W$. Bockermann 3 (SP); $500 \mathrm{~m}$ antes do abrigo Macieiras, elev. 1.900 m, 25/IV/1989 (fl), $A$. Costa 268 (RB); Subida ao Planalto, 30/I/1975 (fl), G. Hastchbach et al. 35834 (MBM); elev. $2.120 \mathrm{~m}, 24 / \mathrm{I} / 1987$ (fl), R. Mello-Silva et al. 9 (SPF).

Alstroemeria radula é rara e encontrada em matas de altitude, em solo arenoso de duas localidades restritas do Espírito Santo e Rio de Janeiro. Floresce de janeiro a junho.

A espécie é de fácil reconhecimento pelas flores de forma peculiar, com tépalas lanceoladas de ápice caudado, reflexas, e os estames e estigma bem longos.

A. radula e $A$. foliosa são simpátridas, porém facilmente diferenciadas. Enquanto que A. radula possui as folhas membranáceas concentradas no terço distal do ramo vegetativo, pedicelo papiloso no terço proximal e tépalas lanceoladas reflexas, A. foliosa possui as folhas cartáceas, distribuídas por todo o ramo vegetativo, pedicelo glabro e tépalas externas obovadas e internas elípticas, não reflexas.

O ápice caudado das tépalas de $A$. radula, levou Ravenna a descrever $A$. caudiculata. Observando-se o material-tipo das duas espécies, fica claro que pertencem a mesma espécie.

\section{Bomarea Mirb.}

Plantas eretas ou escandentes, raízes tuberosas ovóides. Ramos volúveis, cilíndricos, glabros, foliosos. Folhas resupinadas, face abaxial papilosas raro glabras, lâminas lineares, lanceoladas ou oblongas. Inflorescência cimeira umbeliforme composta por inflorescências parciais, brácteas foliosas. Flores bissexuais, epígenas, mais ou menos actinomorfas; perianto infundibiliforme a campanulado; tépalas externas sem máculas, obovada-oblongas; internas rubro-maculadas na face adaxial, espatuladas; estames 6; anteras basifixas, oblongas, de deiscência introrsa e longitudinal; ovário trilocular, óvulos anátropos, placentação axilar ou parietal, estilete filiforme, estigma trífido. Fruto cápsula loculicida, depressa, turbinada, truncada no ápice. Sementes numerosas, subglobosas, sarcotesta de cor roxo-laranja brilhante.

O gênero inclui aproximadamente 100 espécies distribuídas pelo Neotrópico. No Brasil, ocorre somente a espécie Bomarea edulis amplamente distribuída pelas matas.

Bomarea edulis (Tussac) Herb., Alstroemeria edulis Tussac, Flora Antillarum 1: 109-112. 1808.

Tipo: Tussac, loc. cit.: pl. 14, fig. 1-6.

Figura 2: f-g

Plantas volúveis, até ca. $5 \mathrm{~m}$ alt., raízes de reserva ovóides. Folhas resupinadas, oblongas ou oblongo-lanceoladas, ca. 3,5-18 x 0,6-5 cm, ápice acuminado a cuspidado, face abaxial papilosa, raro glabra. Cimeira umbeliforme composta, pauci- ou multiradiada. Flores rosadas, esverdeadas creme ou amareladas, 3-4,5 cm compr. Tépalas externas sem manchas, oblanceoladas, oblongas ou obovadas, 2,6-4 x 1-1,5 cm. Tépalas internas espatuladas, ápice retuso ou mucronado, 2,5$3,5 \times 1-1,2 \mathrm{~cm}$, rubro-punctadas e variegadas. Sementes com sarcotesta vermelha-alaranjada. Material examinado: Angra dos Reis: Ilha Grande. 2/XII/1980 (fl), D. Araújo et al. 4114 (GUA); 14/XII/1983 (fl), M. B. Casari et al. s/n (GUA 26537); 19/XII/1984 (fl), D. Araújo et al. 6489 (GUA); 11/III/1986 (fr.) D. Araújo et al. 7288 (GUA); 28/XI/1989 (fl), D. Araújo \& M. V. S. Alves 9043 (GUA); 23/XI/1990 (fl), C. A. L. de Oliveira et al. 910 (GUA); 1/XII/1992 (fl), D. Araújo 9705 (GUA); Parati: 20/X/1978 (fl), D. Araújo \& R. F. de Oliveira 2254 (GUA); Parati-Mirim: 7/XII/1976 (fl), D. Araújo et al. 1404 (GUA); Resende: Serrinha, $430 \mathrm{~m}$ alt. 14/II/1988 (fl), R. B. Pineschi et al. 405 (GUA); Rio de Janeiro: IV/1883 (fl), A. Glaziou 14346 (K); Jacarepaguá. 17/VII/1932 (fl), M. Rosa s/n 
(R 50394); Pedra Branca. 24/XII/1973 (fl), $P$. Carauta \& L. Sobrinho 1691 (GUA); Grumari. 28/X/1971 (fl), D. Sucre $s / n$ (RB 154.694); 11/III/1983 (fr.) D. Araújo \& N. C. Maciel 5482 (GUA); Santa Maria Madalena: Parque Estadual do Desengano, Serra da Morumbeca. 16/II/1978 (fl), M. C. Vianna et al. 1296 (GUA).

Espécie neotropical, amplamente distribuída pelo Brasil no interior e beira de matas. Floresce principalmente de novembro a janeiro.

Bomarea edulis apresenta variação tanto nas folhas, que podem ser largas, estreitas, pubescentes ou glabras, como nas flores, que variam de róseas ou creme-esverdeadas, e na inflorescência que se apresenta com muitas ou poucas flores. Seu hábito volúvel e sua inflorescência umbeliforme, em geral bem vistosas, são caracteres marcantes que as distinguem do resto da família.

Usos: Raízes de reserva comestíveis.

\section{Agradecimentos}

Este trabalho faz parte da tese de doutorado desenvolvida pela autora no Departamento de Botânica do Instituto de Biociências da Universidade de São Paulo sob a orientação do Dr. Renato de Mello-Silva. Agradeço a Empresa Brasileira de Pesquisa Agropecuária (EMBRAPA) e a Fundação Margaret Mee pelas bolsas concedidas, e aos curadores dos herbários que permitiram a análise dos materiais disponíveis nas coleções.

\section{REFERÊNCIAS BIBLIOGRÁFICAS}

Aker, S. \& Healy, W. 1990. The phytogeography of the genus Alstroemeria. Herbertia 46(2): 76-94.

Assis, M. C. 2001. Alstroemeria L. (Alstroemeriaceae) do Brasil. Tese de doutorado. Universidade de São Paulo, São Paulo.

2002. Novas espécies de Alstroemeria L. (Alstroemeriaceae) de Minas Gerais, Brasil. Revista Brasileira de Botânica. 25(2): 177-182.
2003. Duas Novas espécies de Alstroemeria L. (Alstroemeriaceae) para o Brasil. Acta Botanica Brasilica 17(2): 179-182.

Assis, M. C. \& Mello-Silva, R. 2002. Flora da Serra do Cipó, Minas Gerais: Alstroemeriaceae. Boletim de Botânica da Universidade de São Paulo. 20: 49-52.

Bayer, E. 1897. Die Gattung Alstroemeria in Chile. Mitteilungen der Botanischen Staatssammlung München 24: 1-362.

Beauverd, G. 1906. Alstroemeria damaziana. Bulletin. de L'Herbier. Boissier 2(6): 587, fig. 1-2.

Sanso, A. M. and Xifreda, C. C. 1999. The synonymy of Schickendantzia with Alstroemeria (Alstroemeriaceae). Systematics and Geographyc of Plants 68: 315-323.

. 2001. Generic Delimitation between Alstroemeria d Bomarea (Alstroemeriaceae). Annals of Botany 88: 1057-1069.

Sanso, A. M; Assis, M. C. and Xifreda, C. C. 2004. Alstroemeria: A charming genus. Acta Horticulture (no prelo). 